\title{
Safety Performance in Industrial Construction: A Case Study
}

\author{
Ahmed Senouci $^{1}$, Ali Jedinia ${ }^{2}$, Neil Eldin ${ }^{1}$ \\ 1. Department of Construction Management, University of Houston, Houston, TX 77204, USA \\ 2. SBM Offshore, Houston, Texas, USA \\ E-mail:asenouci@uh.edu
}

Received: 17 June 2021; Accepted: 16 August 2021; Available online: 30 September 2021

\begin{abstract}
This paper presents a case study of a safety training program developed by an international leading construction firm. The study was prompted by the continuing challenge of work- related accidents in the construction industry. Even with the measurable safety improvements in the last several decades, the construction industry still exhibits high rate of occupational fatal injuries compared to other industries. A linear regression model was developed using Microsoft Excel to determine the level of impact of the number of training hours on the resulting safety performance. The analysis confirmed that the number of training hours had a strong impact on reducing safety incidents. The coefficient of determination $\left(\mathrm{R}^{2}\right)$ demonstrated that the number of training hours accounted for $81 \%$ of the variance in the incidents rate. The study results should assist in quantifying the costbenefits of implementing safety programs, and in justifying the mandating of a certain number of training hours. Keywords: Industrial construction safety; Safety training programs; Incident rates; Linear regression applications; Statistical analysis in industrial construction.
\end{abstract}

\section{Introduction}

The efforts invested in enhancing construction safety by the Occupational Safety and Health Act (OSHA), the National Occupational Safety and Health (NIOSH), the Construction Industry Institute (CII), and many leading engineering-construction firms have made a measurable positive impact on the construction safety records [1-3]. For example, the annual number of deaths decreased from 14,500 in 1933 to 5,100 in 1997 [4]. It is noteworthy that this improvement in safety performance was realized while the construction workforce more than tripled since 1933. However, Table 1 shows that the construction industry is still far from reaching its target of zero incidents [3].

Table 1. Fatal Occupational Injury Rates (Deaths per 100,000 Workers) *

\begin{tabular}{cccc}
\hline Mining & $\begin{array}{c}\text { Agriculture/ } \\
\text { Forestry/Fishing }\end{array}$ & Construction & $\begin{array}{c}\text { Transportation/ } \\
\text { Communications/Public Utilities }\end{array}$ \\
\hline 30.3 & 20.1 & 15.2 & 13.4 \\
\hline
\end{tabular}

Since hazards cannot be totally removed from construction activities, the best practical approach to improving safety is to train the workers to create a safer work environment and prevent exposure to possible hazards [5].

This paper presents a safety program developed by a leading company in the construction industry to improve its safety records. In this case study, the company's safety incidents rate was correlated to the number of training hours received by the workers. The data presented in this paper covers a study period of four years (2012 - 2016). Due to confidentiality requirements, the name of the firm and the details of the projects could not be revealed.

\section{Construction safety overview}

The construction safety training topic has attracted many researchers for many years. Langford et al. [6] have reported that safety training for both workers and managers is critical to improve the safety performance across the construction industry. Wilkins [7] reported that implementing safety training programs improve the overall compliance with the health and safety laws and regulations. Hung et al. [8] have observed that significant differences in safety attitudes and risk perceptions could be achieved by interventions such as implementing informal training to supplement formal training. Tam and Fung [9] concluded that mandatory training could improve people's attention to their personal safety. Shin et al. [10] have reported that work-based training provides workers with direct experience of workplace processes and safety incidents and improves their safety attitudes. 
Rodríguez-Garzón et al. [11] also reported that safety training is a major factor in improving the safety perceptions and safety behavior on construction projects.

Burke et al. [12] and Bahn \& Barratt-Pugh [13] reported that training is more effective when it is engaging and results in a greater knowledge acquisition, a higher level of safety performance, and a greater reduction in accidents. Namian et al. [14, 15] emphasized the importance of using innovative learning techniques to facilitate high engagement in safety training.

Also, many researchers explored the use of new technologies in enhancing safety training in construction. These technologies include web-based applications, e-learning, videos, and virtual reality [16-22]. Many researchers explored the challenges associated with providing effective safety training for minority groups in the construction industry [23-25]. Examples of such challenges involved methods of communications, language proficiency, and the value of visualization techniques (e.g., cartoons). Loosemore and Malouf [26] studied safety training in the Australian construction industry. They recommended that more attention should be given to the demographic characteristics of the people being trained and to the use of new interactive, immersive technologies, and learnercentric andragogy when developing safety training programs. Mehany et.al. [27] conducted an evaluation of the effects of the delivery methods on safety training and knowledge retention. They found no significant differences based on the training delivery methods. Shepherd et.al. [28] conducted a study on the challenges affecting the safety of migrant workers in the construction industry in Italy, Spain, and the UK. They reported that language barriers, use of large number of subcontractors, dilution of safety standards through the supply chain, pressure to breach safety regulations, differing safety attitudes/behaviors due to cultural differences are typical examples of such challenges.

In the United States, the Occupational Safety and Health Act [29] identified the employers' responsibilities regarding the workers' safety training requirements. The management staff (e.g., Foremen, Superintendents, Project Managers, Safety Coordinators, and Safety Specialists) are required to attend an OSHA 30-hour Construction Training course, and to obtain the OSHA 30-hour card. In Australia, safety training is a compulsory requirement. In the UK, employers must ensure that their supply chain including consultants, subcontractors, and suppliers have the appropriate training that is comparable to the risk presented in the tasks to be undertaken by the workers. In Hong Kong and Singapore, there are similar systems of mandatory safety training [30, 31]. Arif et.al. [32] developed a construction safety framework to produce safety training modules for workers to overcome language restrictions. Kazar and Comu [33] evaluated the effectiveness of serious games for safety training. They have reported a significant increase in the occupational safety knowledge compared to traditional training. They also reported that such safety programs provide effective training that ensures the maintenance of safety knowledge acquired over time.

\section{Safety management approach}

The case study presented here involved a firm that is considered a leader in the oil and gas industry. The firm offers services in project management, engineering, and construction for highly complex projects. It manages industrial assets all over the world and operates a fleet of specialized vessels for offshore construction including platforms and subsea installations.

The firm developed a health, safety, and environment (HSE) program that has been implemented across its projects. The development of this HSE program started with the company leadership defining the safety values that shapes the firm's safety behaviors and expectations. Its leaders realized that the leaders' behavior significantly impact the employees' perception and behavior. And that the leaders' actions could promote the desired HSE culture and improve safety performance. The HSE program comprised a series of interactive training modules for the various job roles within the organization. The top corporate management was committed to the HSE training program and was dedicated to its successful implementation at every level of the organization. The stakeholders of the HSE training program included the firm's employees, clients, contractors, and subcontractors.

The key objective of the training program was to develop a safety culture to ensure that the employees are all healthy, safe, and environmentally responsible. The training strategy was to motivate all employees to nurture an HSE culture across the organization and to achieve excellence in HSE performance.

The firm made it mandatory that all employees must attend at least one safety training course every year. The training courses were tailored to address the entire organization, as listed below:

1) Training for engineers - all engineers and designers.

2) Training for office personnel- all support/shared services, clerical, administrative.

3) Training for field workforce - all personnel on vessels, construction, and fabrication sites.

4) Training for managers and supervisors - all directors, managers, and supervisors.

5) Training for HSE leadership- all leadership personnel in a particular project.

Training for Engineers: This consisted of a one-day module (8 hours) tailored to safety in engineering and design. All engineers and designers from all disciplines and design functions had to attend. This training was 
designed in an interactive and participative style (workshop format). Presentations were brief and served to provide information and to introduce models and concepts. The key learning objectives included safety communication, HSE in design, risk management, maturity models, and safety challenges and solutions.

Training for Office Personnel: This consisted of a half-day module (4.5 hours) and covered safety in the home office and field office environments. All office employees were instructed to attend this training. This training was designed in an interactive and participative style (workshop format). It introduced safety concepts, models, tools, and then gave the participants the opportunity to practice through a number of established scenarios. It also encouraged the participants to share their own experiences. The key learning objectives included the role played by the safety leader, the ingredients of effective communication, and methods of hazard identification, the importance of intervention, and accountability for HSE.

Training for Field Workforce: This consisted of a one-day module (8 hours) designed for construction site employees and visitors. The course included a review of the HSE rules, responsibilities, and accountabilities in enforcing the HSE policies. It introduced practical tools to enable workers and supervisors to integrate HSE into their daily tasks. The course was designed in the format of an interactive and participative workshop. The key learning objectives included effective HSE leadership on site, hazard Identification and key risk conditions on site, effective toolbox talks and communication, rules for stopping the work, discipline and rewards, accountability for safety, and managing changing conditions.

Training for Managers and Supervisors: This consisted of a two-day module (16 hours) that is designed to teach managers and supervisors to be good communicators and leaders regarding the safety of their subordinates. The course included behavioral theories, the Heinrich's Triangle, HSE culture maturity models, behavioral root cause analysis, and understanding the root causes of incidents and accidents, means to prevent accidents, understanding the principles and application of HSE accountability, coaching and communicating without workers becoming defensive, learn to observe and influence without causing concerns, and understanding how to gather and use leading behavioral indicators. This module was also available as a three-day course. The extended format incorporated the Insights Discovery model, provided a deeper understanding of communication and leadership styles, and the impact of the leaders' actions on their subordinates. This 3-day course also included an online questionnaire and the review of an e-learning module prior to attending's the course.

Training for HSE Leadership: This consisted of a two-day module (16 hours) that is designed for individuals with leadership roles. The training was designed to promote the HSE core values, emphasize the importance of the explicit management statements and actions. It underscored the significance of the implicit messages for endorsing the HSE as a core value ("walk the talk"), and the positive impact of day-to-day management behaviors on HSE at the workplace. The course included discussing the development of leadership qualities, understanding of how to promote HSE culture in a project/team environment, reconfirming HSE leadership commitments, identifying project/team challenges, and generating action lists to address such challenges. The training was provided in an interactive and participative workshop format. It required the completion of an online questionnaire (15-20 minutes) prior to the event to generate a personal profile that defines individual preferences in communication, management style, and leadership approach.

All training modules were conducted in a face-to-face modality. This was done to allow the course facilitators to fully answer the attendees' questions and to provide feedback. The facilitators were company employees who received intensive training to become HSE facilitators. Upon the completion of such training, the facilitators were put in a six-day practice period during which they were observed and evaluated by professional HSE evaluators. Upon the successful completion of the practice period, they were certified as facilitators and allowed to conduct training sessions. This standardized training ensured that the same material was offered to all the employees worldwide.

This HSE program offered a behavior-based training that focused on changing the individuals' culture and behavior to promote safe practices, proactively eliminate potential hazards, and to prepare the employees to act safely in hazardous situations. The training program motivated the employees by giving them a sense of empowerment as safety leaders. The program focus was not just directed to enforcing procedures, rules, and regulations mandated by law. Rather, it was directed to changing people's perception and behavior towards safety.

\section{Data collection}

The objective of this study was to establish the mathematical relationship between the safety incidents observed and the training hours received by the employees. Table 2 summarizes the safety data during the period from 2012 to 2016. The work incidents were retrieved from the company's Risk Management Information System, and the training hours were retrieved from the company Training Database. The data represented all the North America employees working on onshore, offshore, and subsea construction sites. The data included: the total number of fatalities, number of injuries, lost time, number of cases requiring restricted work, number of cases requiring 
number of cases requiring medical treatment, number of cases requiring first aid cases, and number of cases of near misses. The data was checked for outliers and potential errors. It was also validated by the company’s officials.

Table 2. Collected Data and Computed Information

\begin{tabular}{|c|c|c|c|c|c|}
\hline \multirow[t]{2}{*}{ Description } & \multicolumn{5}{|c|}{ Years } \\
\hline & 2012 & 2013 & 2014 & 2015 & 2016 \\
\hline Man-Hours & $14,889,323$ & $17,140,736$ & $13,345,163$ & $12,603,376$ & $11,957,587$ \\
\hline Fatalities & 0 & 0 & 0 & 0 & 0 \\
\hline Lost Time Injuries & 4 & 5 & 1 & 2 & 0 \\
\hline Lost Workdays & 349 & 430 & 2 & 185 & 0 \\
\hline Restricted Work Cases & 8 & 8 & 2 & 4 & 0 \\
\hline Restricted Workdays & 83 & 76 & 56 & 93 & 0 \\
\hline Medical Treatment Cases & 11 & 15 & 11 & 3 & 2 \\
\hline Recordable Cases $(4+5+7)$ & 23 & 28 & 14 & 9 & 2 \\
\hline First Aid Cases & 162 & 253 & 147 & 103 & 162 \\
\hline Near-Miss Incidents & 136 & 175 & 120 & 88 & 112 \\
\hline $\begin{array}{l}\text { Fatal Accident Rate (per 200k hours } \\
\text { worked) }\end{array}$ & 0 & 0 & 0 & 0 & 0 \\
\hline $\begin{array}{l}\text { Lost Time Injury Frequency (per } \\
\text { 200k hours worked) }\end{array}$ & 0.05 & 0.06 & 0.01 & 0.03 & 0.00 \\
\hline $\begin{array}{l}\text { Total Recordable Incident Rate w/ } \\
\text { Subs (per 200k hours worked) }\end{array}$ & 0.31 & 0.33 & 0.21 & 0.14 & 0.03 \\
\hline $\begin{array}{l}\text { Lost Time Frequency Rate (per } 1 \\
\text { million hours worked) }\end{array}$ & 027 & 0.29 & 0.07 & 0.16 & 0.00 \\
\hline $\begin{array}{l}\text { Total Recordable Frequency Rate } \\
\text { (per } 1 \text { million hours worked) }\end{array}$ & 1.54 & 1.63 & 1.05 & 0.71 & 0.17 \\
\hline $\begin{array}{l}\text { DART (Days Away, Restricted, } \\
\text { Transferred Case Frequency) }\end{array}$ & 0.16 & 0.15 & 0.04 & 0.10 & 0.00 \\
\hline
\end{tabular}

Two measures constituted the variables in the analysis: a) the number of training hours, and b) the annual Total Recordable Case Frequency (TRCF) per 200,000 man-hours. A linear regression analysis was used to test the significance of the relationship between the training hours and the incident rates.

Table 3 summarizes the total number of training hours, and Figure 1 graphically presents the annual and cumulative training hours that the employees received.

Table 4 summarizes the values of the dependent variable (TRIR) and the independent variable (Training Hours).

Table 3. Total and cumulative training hours from 2012 to 2016.

\begin{tabular}{lccccc}
\hline \multicolumn{1}{c}{ Year } & 2012 & 2013 & 2014 & 2015 & 2016 \\
\hline Total Pulse Training hours & 14587 & 16004 & 11521 & 17076 & 2046 \\
Cumulative Total Pulse Training hours & 14587 & 30591 & 42112 & 59188 & 61234 \\
\hline
\end{tabular}

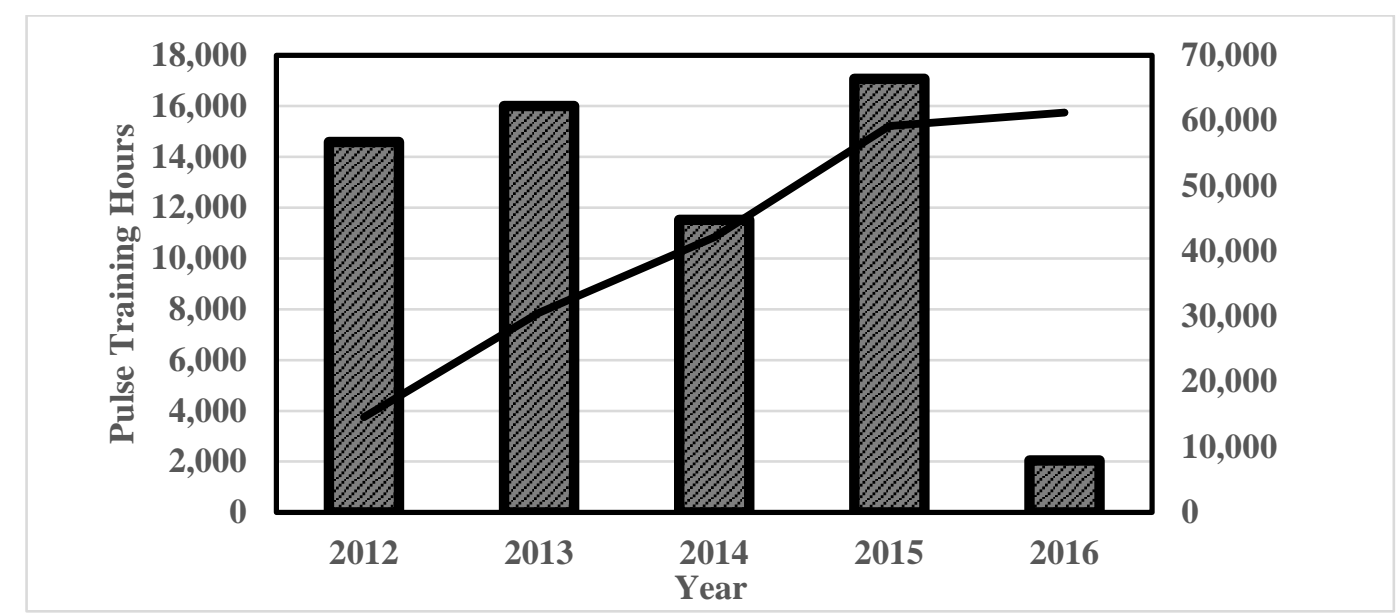

Figure 1. Annual and Cumulative Training Hours 2012 - 2016 
Table 4. TRIR and Training Hours

\begin{tabular}{cccccc}
\hline Years & $\mathbf{2 0 1 2}$ & $\mathbf{2 0 1 3}$ & $\mathbf{2 0 1 4}$ & $\mathbf{2 0 1 5}$ & $\mathbf{2 0 1 6}$ \\
\hline TRIR & 0.31 & 0.33 & 0.21 & 0.14 & 0.03 \\
Training hours & 14.60 & 30.60 & 42.10 & 59.20 & 61.20 \\
\hline
\end{tabular}

\section{Linear regression analysis}

Linear regression is customarily used to determine the relationship between two variables [34-36]. In the case study presented, these are the safety incident rates (dependent variable) and the training hours (independent variable). Microsoft Excel was used to formulate a linear regression equation to model the relationship between the incident rates (TRIR) and the safety training hours. In its simplest form, the model can be developed using the following equation [34-36]:

$$
\mathrm{Y}_{\mathrm{i}}=\beta_{0}+\beta_{1} \mathrm{X}_{\mathrm{i}}+\varepsilon_{\mathrm{i}}
$$

where $Y_{i}$ is the value of the response variable in the ith trial, $\beta_{0}$ and $\beta_{1}$ are the regression parameters; $X_{i}$ is the value of the predictor variable in the $\mathrm{i}^{\text {th }}$ trial; and $\varepsilon_{\mathrm{i}}$ is the random error. The equation resulting from the best-fit curve is expected to have variation errors that are independent of the predictor values, constant for all variable values, and normally distributed at each predictor value.

The following equation presents the regression model for the data collected:

$$
\mathrm{Y}_{\mathrm{i}}=0.4402-5.867 * 10^{-6} \mathrm{X}_{\mathrm{i}}
$$

Four selection criteria were used to validate the suitability of this model. These criteria were the correlation coefficient $(\mathrm{R})$, the coefficient of determination $\left(\mathrm{R}^{2}\right)$, the adjusted $\left(\mathrm{R}^{2}\right)$, and the standard error (S or MSE).

Table 5 provides the regression model descriptive statistics. The correlation coefficient (R) was found to be equal to -0.901, which indicates a strong negative correlation between TRIR (incident rates) and the training hours. In other words, it confirmed that incident rates (TRIR) should decrease with the increase of the training hours. The regression analysis had an $\mathrm{R}^{2}$ of .812, which indicates a high correlation between the dependent and independent variables. It also suggests that the independent variable (training hours) accounts for $81 \%$ of the variance in TRIR.

Table 5. Regression Model Descriptive Statistics

\begin{tabular}{ccccc}
\hline Multiple $\mathrm{R}$ & $\mathrm{R}^{2}$ & $\mathrm{R}^{2}$-Adjusted & Standard Error & Observations \\
\hline 0.901 & 0.812 & 0.749 & 0.062 & 5 \\
\hline
\end{tabular}

The relationship between the training hours and TRIR is also shown graphically in Figure 2. As can be seen in the Figure, a strong negative linear relationship exists between the TRIR and the training hours.

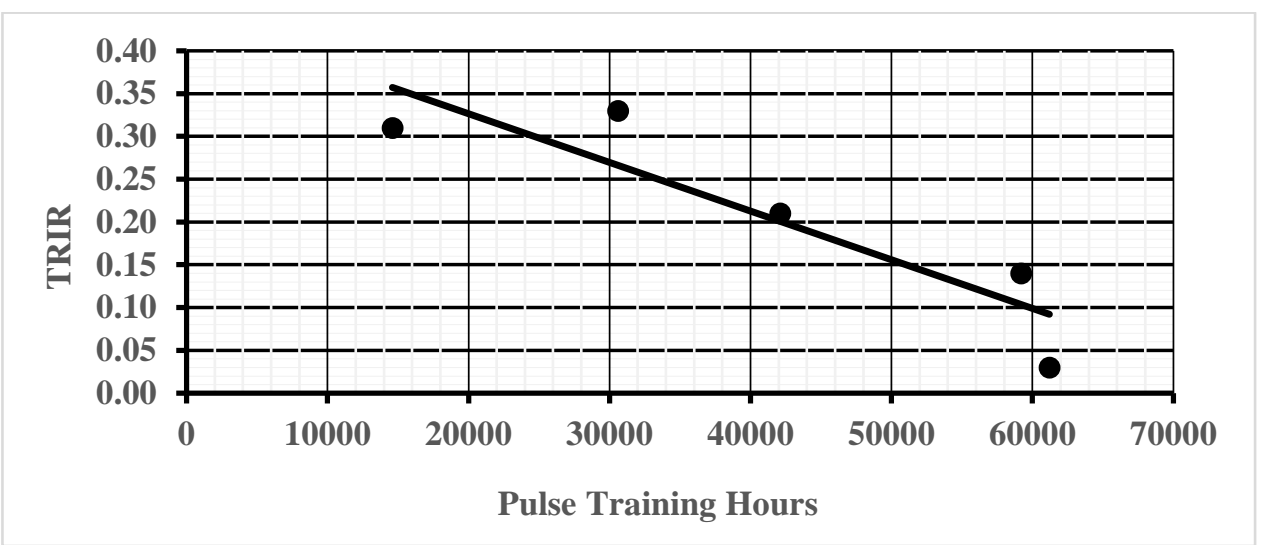

Figure 2. TRIR versus Training Hours.

Several tests were conducted to confirm that the above regression model was statistically sound. The tests included the F-test and the t-test for each regression parameter " $\beta_{\mathrm{k}}$ ". Table 6 summarizes the results of the statistical tests. 
Table 6. ANOVA Test Results

\begin{tabular}{cccccc}
\hline ANOVA & df & SS & MS & F & Significance F \\
\hline Regression & 1 & 0.050 & 0.050 & 12.942 & 0.037 \\
Residual & 3 & 0.012 & 0.004 & & \\
Total & 4 & 0.06152 & & & \\
\hline
\end{tabular}

The F-test was conducted to determine the F value for the entire model. A hypothesis test was carried out in which the null hypothesis $\left(\mathrm{H}_{0}\right)$ assumed that the values of the regression coefficients are zero (i.e., $\beta_{0}=\beta_{1}=0$ ). The alternate hypothesis $\left(\mathrm{H}_{\mathrm{a}}\right)$ assumed that at least one of the coefficients is not equal to zero. As can be seen in the table, the F-value (statistical significance) is 12.942, while the critical value for F is 0.037 . In other words, the null hypothesis is rejected, and hence at least one coefficient in the developed regression equation is not equal to zero.

The t-test was performed to check the significant effect of the predictor related to the response variable. $T_{0}$ determine the validity of the regression coefficient individually, t-tests were performed separately for $\beta_{0}$ and $\beta_{1}$. The t-test for the null hypothesis $\left(\mathrm{H}_{0}\right)$ assumed that $\beta_{0}=0$, while it assumed that $\beta_{0} \neq 0$ for the alternative hypothesis (Ha). Similarly, the other null hypothesis assumed that $\beta_{1}=0$ and for the alternative hypothesis $\left(\mathrm{H}_{\mathrm{a}}\right)$.

Table 7 summarizes the results of the t-test. It is quite clear that both coefficients are accepted at a maximum $\mathrm{P}$ value of $3.68 \%$. In other words, the results show that the developed model is statistically sound. The analysis results have confirmed that the training hours had a strong impact on reducing the safety incident rates (TRIR).

Table 7. Regression Model Coefficient t-Test Results

\begin{tabular}{cccccc}
\hline Coefficients & Values & Standard Error & t-Statistic & P-Value & $\alpha$-Value \\
\hline$\beta_{0}$ & 0.4402 & 0.0713 & 6.1743 & 0.0086 & 0.0500 \\
$\beta_{1}$ & $-5.8671 * 10^{-6}$ & $1.5808 * 10^{-6}$ & -3.5976 & 0.0368 & 0.0500 \\
\hline
\end{tabular}

\section{Conclusions}

This paper presented a brief description of a safety program developed by one of the leading international construction companies. The lease safety program focused on creating a strong safety culture by mandating safety training that emphasized the importance of safety leadership more than merely focusing on procedures. The paper also presented a regression model to qualitatively the impact of the safety training hours on the reduction of the safety incident rates for the firm. The regression model was developed using actual data collected over four years (2012 - 2016). The model was developed based on the total number of safety incidents (i.e., fatalities, lost time injuries, restricted work cases, and medical treatments) and the training hours that the employees received. The correlation coefficient $\mathrm{R}$, the coefficient of determination $\mathrm{R}^{2}$, the adjusted $\mathrm{R}^{2}$, and the standard error $\mathrm{S}$ or MSE were used to validate the regression model. The correlation coefficient $\mathrm{R}$ was found to be equal to -0.901 . This indicated that a strong negative correlation existed between the training hours and the safety incident rates. The coefficient of determination $\mathrm{R}^{2}$ was found to be equal to 0.812 . This indicated that the training hours accounted for $81 \%$ of the variance in observed incident rates. The regression model confirmed that the safety training had a significant effect on the reduction of safety incidents. The safety training program has significantly reduced the incident rates (TRIR) across the firm's construction projects worldwide. However, the authors realize that the developed model was limited to the operations of one. To ensure the applicability of the presented model across the construction industry, the authors plan on repeating the same study using data from a number of similar construction firms.

\section{References}

[1] Stout RJ, Cannon-Bowers JA, Salas E. The role of shared mental models in developing team situational awareness: Implications for training. Training Research Journal. 1996; 85-116

[2] Bonnie RJ, Fulco CE, Liverman CT. Reducing the Burden of Injury Advancing Prevention and Treatment Institute of Medicine (US) Committee on Injury Prevention and Control. Washington (DC): National Academies Press (US).

[3] CDCP. Achievements in Public Health, 1900-1999. Morbidity and Mortality Weekly Report. 1999; 48(22).

[4] National Safety Council. Accident facts. Illinois: Itasca. 1998.

[5] Weinstock D, Slatin C. Learning to Take Action: The Goals of Health and Safety Training. New Solutions. 2012; 22(3): 255-267.

[6] Langford D, Rowlinson SM, Sawacha E. Safety behavior and safety management: its influence on the attitudes of workers in the UK construction industry. Eng., Construct. Archit. Manage. 2000; 7 (2):133-140. 
[7] Wilkins JR. Construction workers' perceptions of health and safety training programs. Construction Management and Economics. 2011; 29 (10): 1017-1026.

[8] Hung Y-H, Smith-Jackson T, Winchester W. Use of attitude congruence to identify safety interventions for small residential builders. Construction Management and Economics. 2011; 29 (2):113-130.

[9] Tam CM, Fung IH. Behavior, attitude, and perception toward safety culture from mandatory safety training course. Journal of Professional Issues in Engineering. 2012; 138 (3):207-213.

[10] Shin M, Lee H, Park M, Moon M, Han S. A system dynamics approach for modeling construction workers safety attitudes and behaviors. Accident Analysis Prevention. 2014; 68 (1): 95-105.

[11] Rodríguez-Garzón I, Lucas-Ruiz V, Martínez-Fiestas M, Delgado-Padial A. Association between perceived risk and training in the construction industry. Journal of Construction Engineering Management. 2015; 141 (5): 453-468.

[12] Burke MJ, Sarpy SA, Smith-Crowe K, Chan-Serafin S, Salvador RO, Islam G. Relative effectiveness of worker safety and health training methods. American Journal of Public Health. 2006; 96(2):315-324.

[13] Bahn S, Barratt-Pugh L. Safety training evaluation: The case of construction induction training and the impact on work-related injuries in the Western Australian construction sector. International Journal of Training Research. 2014;12(2):148-157.

[14] Namian M, Albert A, Zuluaga CM, Behm M. Role of safety training: impact on hazard recognition and safety risk perception. J. Construct. Eng. Manage. 2016; 142 (12).

[15] Namian M, Albert A, Zuluaga CM, Jaselskis EJ. Improving hazard-recognition performance and safety training outcomes: integrating strategies for training transfer. J. Construct. Eng. Manage. 2016;142 (10).

[16] Carney M, Wall J, McNamee F, Madden D, Hurst A, Vrasidas C, Chanquoy L, Baccino T, Acar E, ÖnwyYazici E. Challenges to delivering safety training through virtual classes. In: Dainty A. (Ed.), Proceedings 24th Annual ARCOM Conference, 1-3 September 2008, Cardiff, UK. Association of Researchers in Construction Management. p. 1075-1082.

[17] Acar E, Wall J, McNamee F, Carney M, Öney-Yazici E. Innovative safety management training through elearning. Architectural Engineering and Design Management. 2008; 4(3): 239-250.

[18] Kamardeen I. Web-based tool for affective safety training in construction. In: Association of Researchers in Construction Management, ARCOM 2011 - Proceedings of the 27th Annual Conference. 2011.p. 309-318.

[19] Sacks R, Perlman A, Barak R. Construction safety training using immersive virtual reality. Faculty of Civil and Environmental Engineering, Technion Campus, Haifa 32000, Israel. 2013a.

[20] Sacks R, Perlman A, Barak R. Construction safety training using immersive virtual reality. Faculty of Civil and Environmental Engineering, Technion Campus, Haifa 32000, Israel. 2013b.

[21] Albert A, Hallowell MR, Kleiner B, Chen A, Golparvar-Fard M. Enhancing construction hazard recognition with high-fidelity augmented virtuality. Journal of Construction Engineering and Management. 2014; 140 (7): 456-475.

[22] Edirisinghe R, Lingard H, Broadhurst D. Exploring the potential for using video to communicate safety information to construction workers: case studies of organizational use. In: Raiden A, Aboagye-Nimo E. (Eds.), Proceedings 31st Annual ARCOM Conference, 7-9 September 2015, Lincoln, UK. Association of Researchers in Construction Management. p. 519-528.

[23] Trajkovski S, Loosemore M. Safety implications of low-English proficiency among migrant construction site operatives. International Journal of Project Management. 2006; 24 (4): 446-452.

[24] Ulubeyli S, Arslan V, Kivrak S. A semiotic analysis of cartoons about occupational health and safety issues in the construction workplace. Construction Management and Economics. 2015; 33 (5):467-483.

[25] Chan APC, Javed AA, Lyu S, Hon CKH, Wong FKW. Strategies for improving safety and health of ethnic minority construction workers. Journal of Construction Engineering and Management. 2016; 142 (9):187201.

[26] Loosemore M, Malouf N. Safety training and positive safety attitude formation in the Australian construction industry. Safety Science. 2019; 113: 233-243.

[27] Mehany MS, Killingsworth J, Shah S. An evaluation of training delivery methods' effects on construction safety training and knowledge retention - A foundational study. International Journal of Construction Education and Research. 2021; 17(1).

[28] Shepherd R, Lorente L, Vignoli M, Nielson K, Peiro JM. Challenges influencing the safety of migrant workers in the construction industry: A qualitative study in Italy, Spain, and the UK. Safety Science. 2021; 142. 105388.

[29] United States 'Occupational Safety and Health Act of 1970. 91st Congress, S.2193, December 29, 1970.

[30] Singaporean Government. Workplace safety Singaporean Workplace Safety and Health Act 2006, Workplace Health and Safety Council. 2006. https://www.mom.gov.sg/legislation/ workplace-safety-and-health.

[31] Singaporean Ministry of Manpower. Singaporean Workplace Safety and Health Act 2006, Workplace Health and Safety Council. 2006. https://www.mom.gov.sg/legislation/ workplace-safety-and-health. 
[32] Arif M, Nasir AR, Thaheem MJ, Khan KIA. ConSafe4All: A framework for language friendly safety training modules. Safety Science. 2021;141: Article\#105329.

[33] Kazar G, Comu S. Effectiveness of serious games for safety training: A mixed method study. Journal of Construction Engineering and Management. 2021; 147(8). DOI: 10.1061/(ASCE)CO.1943-7862.0002119.

[34] Montgomery DC, Peck EA, Vining GG. Introduction to Linear regression Analysis, Fifth Edition. Wiley, John Wiley \& Sons, Inc. 2012.

[35] Montgomery DC, Runger GC. Applied Statistics and Probability for Engineers, 7th Edition. Wiley, John Wiley \& Sons, Inc. 2018.

[36] Frost J. Regression Analysis: An Intuitive Guide for Using and Interpreting Linear Models. Jim Publishing. 2019.

(C) 2021 by the author(s). This work is licensed under a Creative Commons Attribution 4.0 International License (http://creativecommons.org/licenses/by/4.0/). Authors retain copyright of their work, with first publication rights granted to Tech Reviews Ltd. 